\title{
QoS Deployment in PTN based Power Communication Networks
}

\author{
Yipeng Li \\ Research Institute of Jiangxi \\ Electric Power Science \\ Nanchang, China, 330096 \\ e-mail: ypligood@163.com
}

\author{
Zheng Wan \\ Jiangxi University of Finance and \\ Economics, \\ Nanchang, China, 330013 \\ e-mail: cloudcity66@yahoo.com.cn
}

\author{
Lingling Zhang, Yu Zhu \\ Research Institute of Jiangxi \\ Electric Power Science \\ Nanchang, China, 330096
}

\begin{abstract}
Abundance of applications requires Power Communication Networks (PCN) to provide large bandwidth and QoS guarantee. PTN, the technique trend of future IP transport network, can meet the requirements. In this paper, we present details of QoS deployment in PTN based PCN of Jiangxi province of China. Firstly, QoS mechanisms of PTN are reviewed. Secondly, PCN topology and services are described. Finally, details of QoS deployments in different kinds of nodes, including $\mathrm{CoS}$ parameters and bandwidth limitations of PW and tunnel, are presented. Such a deployment strategy can help PTN constructions of other province-level PCNs.
\end{abstract} HQoS

Keywords-QoS; Power communication networks; PTN;

\section{INTRODUCTION}

Power Communication Networks (PCN) are special networks constructed for manufacture, management and sell of power grid. Many kinds of services are transmitted in the networks, including dispatching telephone, video and device surveillance of substation, thunder monitoring, video conference, etc. Since Intelligent Power Grid Project is now driven by Chinese government, more and more intelligent applications will emerge, which raise advanced requirements for PCN. Within these requirements, an important one is to provide differentiated QoS guarantee for different services.

The straightforward way to guarantee QoS is to provide sufficient bandwidth, thus requirements of all services could be meet. However, such an ideal condition is always absent. Therefore, effective QoS strategy is needed. To fulfill QoS requirements of all kinds of services, Power systems are beginning to construct PTN (Packet Transport Network) $[1,2,3]$ or PTN+OTN (Optical Transport Network) based PCN to provide more bandwidth and effective QoS mechanisms.

Currently while SDH/MSTP is the main transport network, ethernet switch and routers play the management role in its independent layer. PTN is a new network proposed by ITU to transport all kinds of IP services [5]. Supporting connection-oriented technique, PTN is considered to be capable of provide multi-service to the operators with a single transport plane. Moreover, PTN is able to maximize the utilization of fiber resources and provide high reliability, automatic resource configuration and flexibility to network environments because it has complete OAM architecture, accurate fault location and QoS classification mechanisms [6]. How to improve the efficiency of operation and maintenance is the most important issue in the front of PTN technology. Whatever, it is the technical trend of nextgeneration IP transporting network.

Nowadays, PTN is used mainly in 3G/LTE communication system and is rarely adopted by PCN [7]. In this paper, we design a PTN based PCN architecture for power system of Jiangxi province in China and focus QoS deployment issue to accommodate various services of PCN.

The rest of the paper is organized as follows. Section 2 discusses QoS mechanisms supported by PTN. Service analysis of PCN is described in Section 3. Then Section 4 presents details of QoS deployment in PTN based PCN. Finally, Section 5 concludes and points out future work.

\section{QOS MECHANISMS IN PTN}

PTN supports DiffServ QoS model. When a PTN device acts as DiffServ edge node, it is capable to implement Hierarchical QoS (HQoS) in the node. Figure 1 gives a simplified description on where HQoS mechanisms locate and how they are applied. In a PTN device, there are four QoS levels: V-UNI, PW/QinQ, Tunnel and Port.

(1) $V$-UNI level is designed to distinguish different services. At this level, V-UNI Ingress strategy and V-UNI Egress strategy can be created and applied for source and destination services respectively. V-UNI Ingress strategy helps to establish the mapping between service and its corresponding $\mathrm{CoS}$ (PHB) and queuing strategy. CoS parameters (include CIR, PIR, etc.) are also determined here. Moreover, at this level V-UNI Group can be created to perform bandwidth control on certain combination of multiple V-UNI.

(2) PW/QinQ level locates at network side. A PW/QinQ strategy always matches a V-UNI (if V-UNI group is not created) or a V-UNI group. Bandwidth control can be performed on a PW/QinQ.

(3) Tunnel level. A tunnel always accommodates multiple PWs which have the same destination. On each tunnel we can set a differentiated bandwidth limitation.

(4) At Port level, services, which are originated from different ingress ports but mapped to the same CoS, is aggregated to share a set of $\operatorname{CoS}$ parameters as a whole. 


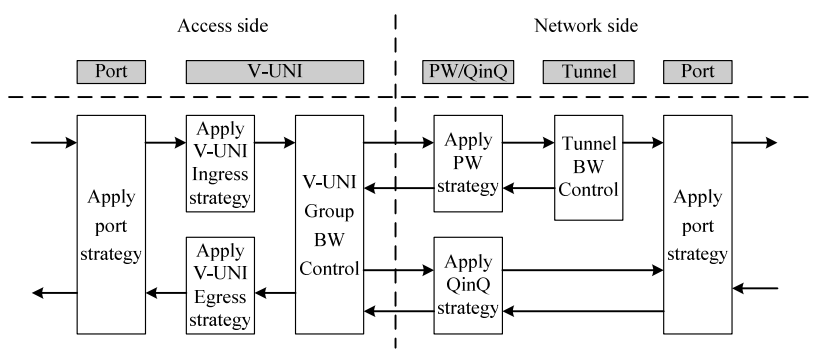

Figure 1. Simplified HQoS framework in PTN

\section{PCN TOPOLOGY OF JIANGXI PROVINCE}

Figure 2 shows the PCN topology of Jiangxi Province, which combines PTN with OTN. At core layer, there are two OTN core loops which are called southwest and northeast core loops. Under the OTN core layer, there is PTN aggregation layer. Each aggregation loop is connected to a core loop through two PTN devices. Similarly, PTN access loop is connected to PTN aggregation loop. Finally, access nodes, including substation, dispatching center and power plant, are connected to the PTN access devices.

\section{SERVICE ANALYSIS OF PCN}

Table 1 shows different services in PCN, which can be classified into four systems: (1) manufacture and dispatching control system; (2) management information system; (3) power sell system; and (4) a system consisting of other services. In this table, RT means real time. The column channel means the channel that the service is transmitted: (1) special line; (2) dispatching data network; (3) data transmission network.

There are four node types in PCN of Jiangxi province: (1) substations which locate in access, aggregation and core loops; (2) power plants which often locate in aggregation and core loops; (3) dispatching centers (together with electric power companies), including province-level, city-level and county-level. County-level center always locates in access

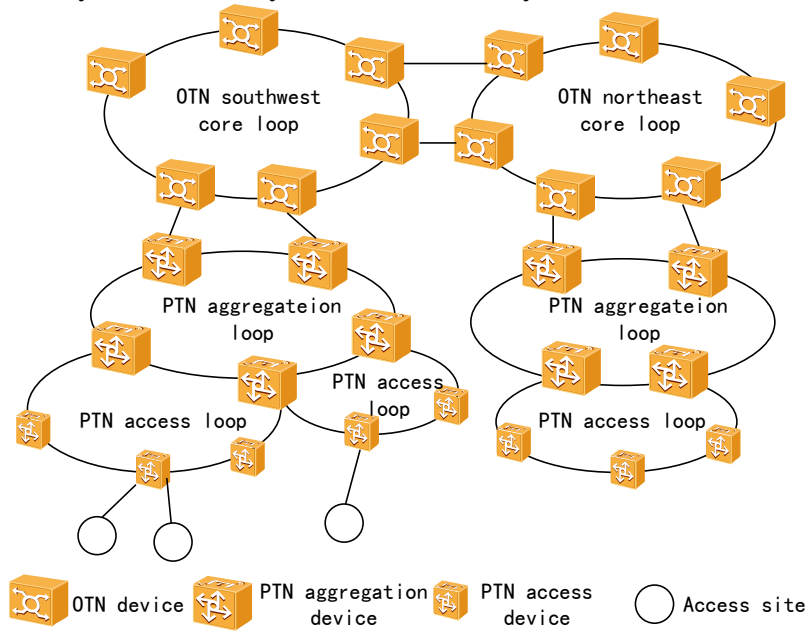

Figure 2. PCN topology of Jiangxi province
TABLE I. SERVICE LIST IN PCN

\begin{tabular}{|c|c|c|c|}
\hline $\begin{array}{l}\text { Service } \\
\text { system }\end{array}$ & Service name & RT? & channel \\
\hline \multirow{11}{*}{ (1) } & Dispatching telephone & Yes & (1) \\
\hline & SCADA/EMS & Yes & (1) \\
\hline & Dispatching automation & Yes & (1) \\
\hline & Running protection management & No & (2) \\
\hline & Running safety management & No & (2) \\
\hline & Power measuring & No & (2) \\
\hline & Power marketing & No & (2) \\
\hline & Dispatcher training (DTS) & No & (2) \\
\hline & Dispatching management & No & (2) \\
\hline & Thunder monitoring & No & (3) \\
\hline & Substation video surveillance & No & (3) \\
\hline \multirow{7}{*}{ (2) } & Financial management system & No & (3) \\
\hline & Material management & No & (3) \\
\hline & Engineering management & No & (3) \\
\hline & Human resource management & No & (3) \\
\hline & Safe manufacture management & No & (3) \\
\hline & Office automation & No & (3) \\
\hline & Administrative telephone & Yes & (3) \\
\hline \multirow{3}{*}{ (3) } & Sell decision making & No & (3) \\
\hline & Sell service management & No & (3) \\
\hline & Sell user management & No & (3) \\
\hline \multirow{6}{*}{ (4) } & Fiber monitoring & No & (3) \\
\hline & Transmission running & No & (1) \\
\hline & Transmission management & No & (3) \\
\hline & Substation device surveillance & No & (3) \\
\hline & Cable monitoring & No & (3) \\
\hline & Video conference & Yes & (1) \\
\hline
\end{tabular}

loop. City-level center often locates in crossover of access and aggregation loops. And the unique province-level center locates in the core loop. (4) Administrative offices, managed by province-level electric power company. The following tables describe services which are transmitted between different node pairs.

TABLE II. SERVICES TRANSMITTED BETWEEN SUBSTATION AND DISPATCHING CENTER

\begin{tabular}{|c|c|c|}
\hline Service name & Direction & Traffic \\
\hline Dispatching telephone & bidirection & $2 \mathrm{M}$ \\
\hline Dispatching automation & bidirection & $2 \mathrm{M}$ \\
\hline Running protection management & substation -> center & $2 \mathrm{M}$ \\
\hline Running safety management & substation -> center & $2 \mathrm{M}$ \\
\hline Power measuring & substation -> center & $2 \mathrm{M}$ \\
\hline Administrative telephone & bidirection & $2 \mathrm{M}$ \\
\hline Substation video surveillance & substation -> center & $20 \mathrm{M}$ \\
\hline Substation device surveillance & substation -> center & $5 \mathrm{M}$ \\
\hline Thunder monitoring & substation -> center & $2 \mathrm{M}$ \\
\hline Cable monitoring & substation -> center & $3 \mathrm{M}$ \\
\hline Fiber monitoring & substation -> center & $2 \mathrm{M}$ \\
\hline
\end{tabular}

TABLE III. SERVICES TRANSMITTED BETWEEN POWER PLANT AND DISPATCHING CENTER

\begin{tabular}{|c|c|c|}
\hline Service name & Direction & Traffic \\
\hline Dispatching telephone & substation $<->$ center & $2 \mathrm{M}$ \\
\hline Dispatching automation & substation $<->$ center & $2 \mathrm{M}$ \\
\hline
\end{tabular}

TABLE IV. SERVICES TRANSMITTED BETWEEN POWER PLANT AND DISPATCHING CENTER

\begin{tabular}{|c|c|c|}
\hline Service name & Direction & Traffic \\
\hline Dispatching telephone & bidirection & $2 \mathrm{M}$ \\
\hline Administrative telephone & bidirection & $2 \mathrm{M}$ \\
\hline
\end{tabular}




\begin{tabular}{|c|c|c|}
\hline SG-ERP & bidirection & $100 \mathrm{M}$ \\
\hline Video conference & bidirection & $8 \mathrm{M}$ \\
\hline Transmission running & bidirection & $10 \mathrm{M}$ \\
\hline Transmission management & bidirection & $10 \mathrm{M}$ \\
\hline Dispatching data network services & bidirection & $155 \mathrm{M}$ \\
\hline
\end{tabular}

TABLE V. SERVICES TRANSMITTED BETWEEN PROVINCE-LEVEL COMPANY AND ITS ADMINISTRATIVE OFFICE

\begin{tabular}{|c|c|c|}
\hline Service name & Direction & Traffic \\
\hline Dispatching telephone & bidirection & $2 \mathrm{M}$ \\
\hline Video conference & bidirection & $8 \mathrm{M}$ \\
\hline Office automation & bidirection & $33 \mathrm{M}$ \\
\hline
\end{tabular}

\section{QOS DEPLOYMENT IN PTN BASED PCN}

\section{A. Considerations and principles}

To determine which mechanisms are needed in a certain node, the following factors should be taken into consideration:

(1) How many ingress ports does the node have? Services transmitted in different channels have different ports. Generally, each service transmitted in special line has an individual port. All the services transmitted in dispatching data network or data transmission network share a port.

(2) Which services does an ingress port have? And what are their types, real-time or not?

(3) What are the sender and the receiver of the services?

(4) How many bandwidths does each service require?

In each node, procedures of QoS deployment are as follows:

(1) Establish the mapping between services and CoSs for each ingress port.

(2) Determine parameters of each CoS.

(3) Determine bandwidth limitation of each PW. (We do not aggregate multiple V-UNIs into V-UNI group, but let each V-UNI match a PW)

(4) Establish the mapping between PWs and tunnels.

(5) Determine parameters of each CoS on port level.

\section{B. QoS deployment details}

QoS mechanisms adopted in different node types are presented in this sub-section.

(1) Substation

Services shown in table 2 are all originated from substation. There are two special line services in each substation: dispatching telephone (denoted as S1) and dispatching automation (S2). The former is real-time voice service and the latter is real-time data service. Both services have a bandwidth requirement of 2Mbps. Running protection management (D1), running safety management (D2) and power measuring (D3) are non-real time data services transmitted in dispatching data network, with 2Mbps bandwidth requirement respectively. The other services are transmitted in data transmission network, among which administrative telephone (T1) is real time voice service and the other are all non-real time data services with different bandwidth requirements.

Table 6 shows details of QoS deployment in a substation (bandwidth unit is Mbps). T2 to T6 denote substation video surveillance, substation device surveillance, thunder monitoring, cable monitoring, fiber monitoring respectively. Column PW means bandwidth limitation of the PW (an ingress port). Since all the services are sent to the countylevel dispatching center, tunnel-level QoS deployment is not required. As for port-level QoS deployment, we can aggregate services that originated from different ingress ports but mapped to the same CoS and let them share a set of CoS parameters. Since port-level deployment is distinct after implementing deployments of other level, it is not presented.

(2) County-level dispatching center

Services in this node have two destinations: substations and city-level dispatching center (Generally, power plants are not managed by county-level dispatching center).

If the destination is substation, there are only three services: dispatching telephone, dispatching automation and administrative telephone. Notice that a county-level center may have several substations.

As for city-level dispatching center, services in table 4 are included. Dispatching telephone, transmission running (S3) and video conference (S4) occupy special lines. Administrative telephone, SG-ERP (T7) and transmission management (T8) services are transmitted in data transmission network. Dispatching data network here is responsible for forwarding data from substations to the higher level dispatching center.

Table 7 shows QoS deployment of services in table 4.

Services of dispatching data network from all substations of county-level center are aggregated to the same port. Bandwidth limitation of PW on this port depends on the number of substations.

TABLE VI. QOS DEPLOYMENT OF SUBSTATION

\begin{tabular}{|c|c|c|c|c|c|c|c|c|c|}
\hline Port & Service & CoS & CIR & PIR & $\begin{array}{c}\text { WRED } \\
\text { begin }\end{array}$ & $\begin{array}{c}\text { WRED } \\
\text { end }\end{array}$ & Queue & $\begin{array}{c}\text { WFQ } \\
\text { weight }\end{array}$ & PW \\
\hline 1 & S1 & EF & 2 & 2 & $100 \%$ & $100 \%$ & PQ & 1 & 2 \\
\hline 2 & $\mathrm{~S} 2$ & AF4 & 2 & 4 & $90 \%$ & $100 \%$ & WFQ & 100 & 4 \\
\hline \multirow{3}{*}{3} & D1 & AF3 & 2 & 4 & $70 \%$ & $90 \%$ & WFQ & 90 & \multirow{3}{*}{10} \\
\hline & D2 & AF3 & 2 & 4 & $70 \%$ & $90 \%$ & WFQ & 90 & \\
\hline & D3 & AF3 & 2 & 4 & $70 \%$ & $90 \%$ & WFQ & 90 & \\
\hline \multirow{6}{*}{4} & T1 & $\mathrm{EF}$ & 2 & 2 & $80 \%$ & $100 \%$ & PQ & 1 & \multirow{6}{*}{50} \\
\hline & $\mathrm{T} 2$ & $\mathrm{AF} 2$ & 20 & 30 & $70 \%$ & $80 \%$ & WFQ & 70 & \\
\hline & T3 & AF2 & 5 & 10 & $70 \%$ & $80 \%$ & WFQ & 70 & \\
\hline & $\mathrm{T} 4$ & AF2 & 2 & 4 & $70 \%$ & $80 \%$ & WFQ & 70 & \\
\hline & T5 & $\mathrm{AF} 2$ & 3 & 6 & $70 \%$ & $80 \%$ & WFQ & 70 & \\
\hline & T6 & AF2 & 2 & 4 & $70 \%$ & $80 \%$ & WFQ & 70 & \\
\hline
\end{tabular}

TABLE VII. QOS DEPLOYMENT OF SERVICES IN TABLE 4

\begin{tabular}{|c|c|c|c|c|c|c|c|c|c|}
\hline Port & Service & CoS & CIR & PIR & $\begin{array}{l}\text { WRED } \\
\text { begin }\end{array}$ & $\begin{array}{c}\text { WRED } \\
\text { end }\end{array}$ & Queue & $\begin{array}{c}\text { WFQ } \\
\text { weight }\end{array}$ & PW \\
\hline 1 & S1 & $\mathrm{EF}$ & 2 & 2 & $100 \%$ & $100 \%$ & $\begin{array}{l}\mathrm{PQ} \\
\end{array}$ & 1 & 2 \\
\hline 2 & S3 & AF3 & 10 & 20 & $80 \%$ & $100 \%$ & WFQ & 90 & 20 \\
\hline 3 & S4 & AF2 & 8 & 20 & $70 \%$ & $80 \%$ & WFQ & 80 & 20 \\
\hline \multirow{3}{*}{4} & $\mathrm{~T} 1$ & EF & 2 & 2 & $80 \%$ & $100 \%$ & $\mathrm{PQ}$ & 1 & \multirow{3}{*}{80} \\
\hline & T7 & $\mathrm{BE}$ & 40 & 100 & $60 \%$ & $70 \%$ & WFQ & 60 & \\
\hline & T8 & AF2 & 10 & 20 & $70 \%$ & $80 \%$ & WFQ & 70 & \\
\hline
\end{tabular}

Then let's discuss QoS deployment at tunnel-level. Firstly, all the services sent to the city-level center can be aggregated into a tunnel, including services in table 7 and services from dispatching data network in the above aggregate port. Secondly, dispatching telephone, dispatching 
automation and administrative telephone services to each substation can be aggregated into a tunnel. Bandwidth limitations of these tunnels depend on the service distribution.

(3) City-level dispatching center

Services in this kind of node have four destinations: substation, power plant, counter-level center and provincelevel center. Notice that a city-level center may have several substations, power plants and counter-level centers.

If the destination is substation, services are the same like those in county-level center. And a tunnel can be created for each substation.

If the destination is counter-level center, services in table 4 are included. For each counter-level center, services are divided into several special lines, a dispatching data network aggregation and a data transmission network aggregation. A tunnel can be created for all these services.

If the destination is province-level center, services are divided into several special lines, several dispatching data network aggregations (multiple county-level aggregations and substation aggregations), and a data transmission network aggregation. All these services can be aggregated into a tunnel.

If the destination is power plant, there are only dispatching telephone and dispatching automation services which can be aggregated into a tunnel.

(4) Province-level dispatching center

Services in this kind of node have four destinations: substation, power plant, city-level center and province-level center. Notice that a city-level center may have several substations, power plants and its administrative offices.

If the destination is substation or power plant, all are the same.

Classification of services and QoS deployment from province-level center to city-level center are the same as those from city-level center to county-level center.

If the destination is administrative office, dispatching telephone, video conference and office automation (T9) services are included. A tunnel can be created for each administrative office. Table 8 shows QoS deployment of services in table 5 .
TABLE VIII. QOS DEPLOYMENT OF SERVICES IN TABLE 5

\begin{tabular}{|c|c|c|c|c|c|c|c|c|c|}
\hline Port & Service & CoS & CIR & PIR & $\begin{array}{c}\text { WRED } \\
\text { begin }\end{array}$ & $\begin{array}{c}\text { WRED } \\
\text { end }\end{array}$ & Queue & $\begin{array}{c}\text { WFQ } \\
\text { weight }\end{array}$ & PW \\
\hline 1 & S1 & EF & 2 & 2 & $100 \%$ & $100 \%$ & PQ & $/$ & 2 \\
\hline 3 & S4 & AF2 & 8 & 20 & $70 \%$ & $80 \%$ & WFQ & 80 & 20 \\
\hline 4 & T9 & BE & 15 & 33 & $60 \%$ & $70 \%$ & WFQ & 60 & 30 \\
\hline
\end{tabular}

\section{CONCLUSION}

In this paper, after analyzing characteristics of services transmitted in power communication networks, we present QoS deployment details of different kinds of nodes, including substation, county-level dispatching center, citylevel dispatching center and province-level dispatching center. For each node we implement hierarchical QoS: (1) $\mathrm{CoS}$ and its corresponding parameters of each service; (2) bandwidth limitations of PW; (3) tunnel construction principle and its bandwidth limitation. Such a deployment strategy can help PTN constructions of other province-level PCNs.

\section{ACKNOWLEDGMENT}

This work was supported by Jiangxi Electric Power Corporation Assisted Project (No. 201250612).

\section{REFERENCES}

[1] Bryant.S, Andersson.L, Joint Working Team (JWT) Report on MPLS Architectural Considerations for a Transport Profile.RFC53 17, 2009.

[2] Mansfield.S, Gray.E, Lam.K.MPLS-TP Network Management Framework. RFC 5950, 2010.

[3] Lam.K, Mansfield.S, GrayE. MPLS-TP Network Management Requirements. RFC 5951, 2010.

[4] Yuanqi Wu, Shuhe Sun, Jiangfeng Chen. Strategy for Intercommunication of PTN and SDH. Proceedings of IC-NIDC2010.

[5] Shuai Lv, Yueming Lu, and Yuefeng Ji. Short-Delay Clock Recovery for CBR Services in PTN. IEEE Communications Letters, 2009, 13(10): 791-793.

[6] Juan Ke, Jun Chang, Rong Zong, Liang Yu, Jinsong Hu. Research on QoS of PTN-based Power Distribution Communication Network. 2011 International Conference on Computer Science and Network Technology (ICCSNT 2011).

[7] Zhang Yong, Yang Jian-Li, Wu Cui-Xian. Design and research on PTN Technology in Local Transport network, 2011 International Conference on Communication Software and Networks (ICCSN 2011). 